\title{
Estudos de conectividade cerebral em linguagem através de Ressonância Magnética funcional.
}

\section{Gabriel Nagamine (IC)}

\section{Resumo}

O cérebro humano é um sistema extremamente complexo e ainda pouco conhecido pelo homem. Nesse contexto, a ressonância magnética funcional (fMRI: functional Magnetic Resonance Imaging) é uma das técnicas mais importantes para o seu estudo e entendimento. Tendo em vista isso, esse projeto teve como objetivos proporcionar familiaridade com análise de dados de fMRI, introduzir o estudante no estudo de conectividade cerebral através da análise de dados colhidos em experimentos de fluência verbal e permitir ao estudante treinamento científico avançado na área de modelagem matemática da atividade cerebral.

Palavras Chave: Neuroimagem, Linguagem, Conectividade.

\section{Introdução}

Ressonância Magnética funcional é uma técnica de imageamento que permite detectar zonas de atividade cerebral mais intensas através do registro de alterações hemodinâmicas e metabólicas associadas a atividade neuronal [1].

A linguagem é um sistema universal complexo e poderoso, cuja essência está ligada ao processamento cerebral entre o sistema sensitivo e motor do cérebro. $O$ imageamento cerebral é uma ferramenta imprescindível na determinação de mapas do processamento da linguagem no cérebro $e$ as técnicas de imageamento por fMRI são a grande esperança para desvendar esse sistema ainda pouco entendido.

Com base nisso, esse presente projeto tem como objetivo a introdução do estudante no estudo de conectividade cerebral através de estudos de linguagem registrados em fMRI, em particular em experimentos de fluência verbal.

\section{Resultados e Discussão}

Um dos objetivos do primeiro período do projeto foi realizar a análise dos dados de fMRI utilizando o software ConnExT (Connectivity Explorer Tollbox). Esse programa fornece uma maneira fácil de explorar visualmente a série temporal do sinal e o mapa de conectividade funcional dos dados de fMRI.

$\mathrm{Na}$ figura a seguir vemos gráficos que representam a série temporal para uma determinada região do cérebro que chamamos de semente. Podemos notar que essa região apresenta uma maior atividade na condição 'LETRA' e menor atividade na condição 'CRUZ', por tanto ela é uma boa região para se utilizar como base para fazer um estudo de conectividade cerebral em um experimento de linguagem.

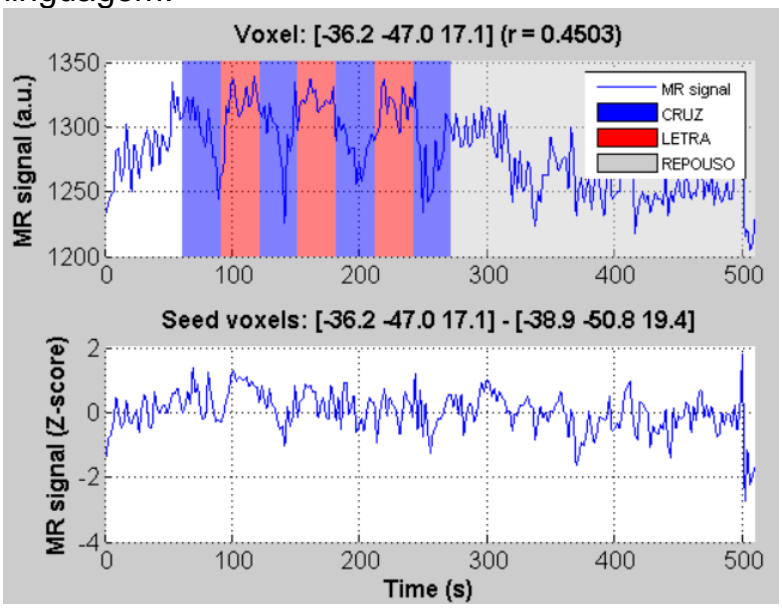

Figura 1. Série temporal em uma determinada região do cérebro obtida através do software ConnExT.

\section{Conclusões}

Nesse projeto foi possível realizar uma introdução ao estudo de conectividade cerebral através da análise de dados de fMRI, particularmente em dados colhidos em experimentos de fluência verbal.

\section{Agradecimentos}

Gostaria de agradecer ao CNPq pelo apoio financeiro e a meus orientadores, Dra, Andréa Alessio e Prof. Roberto Covolan, pelas orientações e ensinamentos fundamentais para a conclusão desse projeto.

\footnotetext{
Buxton, R. B. Introduction to functional Magnetic Resonance Imaging: principles and techniques - Cambridge University Press, 2002 .
} 